\title{
Spectrum of genomic variations in Indian patients with progressive familial intrahepatic cholestasis
}

\author{
Anjali Sharma', Ujjal Poddar², Shikha Agnihotry', Shubha R. Phadke', Surender K. Yachha² and Rakesh Aggarwal ${ }^{1 *}$ (D)
}

\begin{abstract}
Background: Progressive familial intrahepatic cholestasis (PFIC) is caused by variations in ATP8B1, ABCB11 or ABCB4 genes. Data on genetic variations in Indian patients with PFIC are lacking.

Methods: Coding and splice regions of the three genes were sequenced in unrelated Indian children with PFIC phenotype. The variations identified were looked for in parents, 30 healthy persons and several variation databases, and their effect was assessed in-silico.

Results: Among 25 children (aged 1-144 months), nine (36\%) had unique major genomic variations (ATP8B1: 4, ABCB11: 3 and ABCB4: 2). Seven had homozygous variations, which were assessed as 'pathogenic' or 'likely pathogenic'. These included: (i) four amino acid substitutions (ATP8B1: c.1660G > A/p.Asp554Asn and c.2941G > A/p.Glu981Lys; ABCB11: c. 548 T > C/p.Met183Thr; ABCB4: c.431G > A/p.Arg144GIn); (ii) one 3-nucleotide deletion causing an amino acid deletion (ATP8B1: c.1587_1589delCTT/p.Phe529del); (iii) one single-nucleotide deletion leading to frame-shift and premature termination (ABCB11: c.1360delG/p.Val454Ter); and (iv) a complex inversion of 4 nucleotides with a single-nucleotide insertion leading to frame-shift and premature termination (ATP8B1: c.[589_592inv;592_593insA]/p.Gly197LeufsTer10). Two variations were found in heterozygous form: (i) a splice-site variation likely to cause abnormal splicing (ABCB11: c.784 + $1 \mathrm{G}>\mathrm{C}$ ), and (ii) a nucleotide substitution that created a premature stop codon (ABCB4: c.475C > T/p.Arg159Ter); these were considered as variations of uncertain significance. Three of the nine variations were novel.

Conclusions: Nine major genomic variations, including three novel ones, were identified in nearly one-third of Indian children with PFIC. No variation was identified in nearly two-thirds of patients, who may have been related to variations in promoter or intronic regions of the three PFIC genes, or in other bile-salt transport genes.
\end{abstract}

Keywords: Progressive familial intrahepatic cholestasis, Hereditary cholestasis, Genetic variation, Polymorphism

\section{Background}

Progressive familial intrahepatic cholestasis (PFIC) is a group of heterogeneous liver disorders of childhood with disruption of normal secretion of bile salts and/or phospholipids into the bile [1]. It accounts for nearly 10 to $15 \%$ of cases with cholestasis in early childhood, and for a large proportion of pediatric liver transplantation procedures [1]. PFIC is classified into three types, namely PFIC1, PFIC2 and PFIC3, based on detection of causative variations in $\mathrm{ATP} 8 \mathrm{~B} 1, \mathrm{ABCB} 11$ and $\mathrm{ABCB} 4$ genes,

\footnotetext{
* Correspondence: aggarwal.ra@gmail.com

1 Department of Gastroenterology, Sanjay Gandhi Postgraduate Institute of Medical Sciences, Lucknow 226014, India

Full list of author information is available at the end of the article
}

respectively [1]. Several different variations have been reported in each of these genes [2-4]. In PFIC1 and PFIC2, symptoms appear during infancy, whereas in PFIC3, these may be delayed to late childhood or adolescence. Also, characteristically, the serum levels of gamma-glutamyl transpeptidase (GGT) are normal in PFIC1 and PFIC2, but are elevated in PFIC3 [5]. Since the protein encoded by ATP8B1 is also expressed in other body tissues, some PFIC1 patients also have extrahepatic manifestations, such as diarrhea, sensorineural deafness, pancreatic deficiency and growth retardation $[1,6]$. All three forms of PFIC are inherited in autosomal recessive manner [1].

The genomic variations underlying PFIC show geographic heterogeneity. Thus, some variations, such as

(c) The Author(s). 2018 Open Access This article is distributed under the terms of the Creative Commons Attribution 4.0 International License (http://creativecommons.org/licenses/by/4.0/), which permits unrestricted use, distribution, and 
G308V, D554N and I661T in ATP8B1 gene have been observed frequently in Caucasian groups [2, 7], but not in other populations; in these latter groups, other sequence variations have been identified as causing PFIC [8]. Further, in a substantial number of patients with PFIC phenotype, no variation in these three genes can be identified. Some of these cases are related to variations in other genes involved in the secretion of bile salts [9].

Data on PFIC in the Indian population are limited to a few case reports and case series [10-15]. In particular, no information is available on genetic variations in Indian patients with PFIC, except in one patient that we reported recently [16]. Given the genetic heterogeneity underlying the three forms of PFIC, particularly between populations [17], the genomic variations in Indian patients with PFIC may be expected to differ from those reported elsewhere. We therefore decided to study genomic variations in the exonic and splice site regions of the ATP8B1, $\mathrm{ABCB} 11$ and $\mathrm{ABCB} 4$ genes in a group of Indian children with clinical features suggestive of PFIC.

\section{Methods}

\section{Study patients}

The study included children with liver disease with clinical and biochemical findings that suggested a diagnosis of PFIC. The diagnosis was considered in all infants and children presenting with cholestatic liver disease, with no evidence of biliary obstruction on imaging or of another cause of liver injury. Cholestasis was defined in children as jaundice with itching and deranged liver function tests, and in neonates as jaundice with conjugated bilirubin exceeding $20 \%$ of total serum bilirubin (or $>1.0 \mathrm{mg} / \mathrm{dL}$ when total bilirubin was $<5.0 \mathrm{mg} / \mathrm{dL}$ ). All children underwent clinical and laboratory work-up, including screening for TORCH (toxoplasmosis, rubella, cytomegalovirus and herpes virus) group of neonatal infections among infants, screening for metabolic liver disease (non-glucose reducing substances in the urine and assay for galactose-1-phosphate uridyl transferase in red blood cells; serum alpha-fetoprotein levels; and, serum ferritin level and minor salivary gland biopsy in those suspected to have neonatal hemochromatosis), and Alagille syndrome (slit lamp examination, X-ray spine and echocardiography). For patients with symptoms starting after 3 years of age, biochemical tests and liver biopsy examination were done to exclude Wilson disease and autoimmune hepatitis.

Biochemical liver function tests including serum gamma-glutamyl transpeptidase (GGT) levels were measured in all patients. Those with elevated GGT levels were considered to have PFIC3, and those with normal GGT were considered to have PFIC1 or PFIC2. All patients with
PFIC3 underwent MRCP; however, this was done selectively in those with PFIC1/PFIC2. All patients also underwent a liver biopsy as part of their diagnostic workup (not for this study); however, immunohistochemistry for bile salt export protein (BSEP; to diagnose PFIC2) and for multidrug resistance 3 protein (MDR3; to diagnose PFIC3) were not possible.

In families with multiple cases, only one child was studied. For each child, clinical and biochemical data were recorded; in addition, family history of liver disease and history of prominent itching during third trimester of pregnancy in the mother were also noted, and a pedigree tree was drawn with special emphasis on consanguinity. From each subject, venous blood $(\sim 2 \mathrm{ml})$ was collected in EDTA, after obtaining written consent from one of the parents, and genomic DNA was extracted using the phenol-chloroform method [18]. Blood specimens were also collected from their parents, wherever possible. The study was approved by our institution's Ethics Committee.

\section{Laboratory methods and data analysis}

From the genomic DNA, all the coding exons (exons 2 to 28 for each gene) and the surrounding splice site regions were amplified using polymerase chain reaction with specific primers for genes ATP8B1 [19], ABCB11 [20] and ABCB4 [21]. The PCR products were subjected to Sanger sequencing in both directions using a 3130 Genetic Analyzer (Applied Biosystems/ThermoFisher).

The nucleotide sequencing data obtained were analysed using Finch TV (1.4.0) (http://jblseqdat.bioc.cam.ac.uk/ gnmweb/download/soft/FinchTV_1.4/doc/) and Seqtrace (version 0.9.0) (https://code.google.com/archive/p/seqtrace/) softwares. The sequences were then aligned against genomic and messenger RNA reference sequences for ATP8B1 (NG_007148.2, NM_005603.4), ABCB11 (NG_007374.1, NM_003742.2) and ABCB4 (NG_007118.1, NM_000443.3) genes from National Centre for Biotechnology Information (NCBI) database. Each variation observed was manually verified.

The sequence variation identified were looked up in various genomic variation databases [NCBI dbSNP (https://www.ncbi.nlm.nih.gov/projects/SNP/), Human Gene Mutation Database (HGMD) (http://www.hgmd .cf.ac.uk/ac/index.php), Exome Aggregation Consortium (ExAC) (http://exac.broadinstitute.org/), ClinVar NCBI (https://www.ncbi.nlm.nih.gov/clinvar/), 1000 genome browsers (http://www.internationalgenome.org/1000-gen omes-browsers/)]. Further, the effect of each variation on the amino acid sequence of the respective protein was assessed; this was followed by prediction of the effect of amino acid change on the protein function using several bioinformatics tools, namely PROVEAN [22], Mutation Taster [23], Polyphen 2 [24], PhD-SNP [25], 
SIFT [26], SNAP [27], Meta SNP [28]. The effect of sequence variations located near splice sites was predicted using Human Splicing Finder tool [29].

Each genomic sequence variant was then analysed for its pathogenic significance using the standards and guidelines laid down by the American College of Medical Genetics and Genomics and the Association for Molecular Pathology [30]. In brief, these guidelines recommend that sequence variants in a gene should be classified into five categories - 'pathogenic', 'likely pathogenic', 'uncertain significance,' 'likely benign', and 'benign' - based on frequency of the variant in the healthy population, computational data, functional data and segregation data.

\section{Studies in parents and control subjects}

Any 'pathogenic' or 'likely pathogenic' variations identified in the patients were looked for in the parents by amplification and sequencing of the specific exons of the affected gene.

For non-synonymous variations identified in one or more patients, the frequency of minor alleles was assessed by sequencing the genomic DNA from 30 healthy persons.

\section{Results}

The 25 patients included in this study were unrelated to each other, and were aged 1 month to 12 years (median: 15 months; 19 boys). Their clinical and laboratory findings are shown in Table 1. Seven patients were born of consanguineous marriages.

\section{Pathogenic or likely pathogenic sequence variations}

Overall, 9 patients were found to have 9 different major genomic variations (Table 2). Of these, seven were present in homozygous form and each of these was interpreted either as 'pathogenic' or 'likely pathogenic' $(n=7)$. The remaining two variations were present in heterozygous form and were assessed to be 'of uncertain significance' $(n=2)$; in both these patients, no other pathogenic variation was identified. Five of the 7 patients with homozygous variations and none of the two with heterozygous variations reported consanguinity (Fig. 1).

Of the nine patients with significant variations, four had these variations in the ATP8B1 gene, 3 in ABCB11 gene and 2 in $\mathrm{ABCB} 4$ gene. Of the nine variations identified, three (ATP8B1: 1, ABCB11: 2) were novel. Four variations led to a single amino acid substitution, one led to shifting of reading frame and premature truncation, two led to creation of a stop codon at the variation site, one led to an in-frame deletion of one amino acid, and one was predicted to lead to loss of a splice site. The clinical and laboratory findings in the patients with identifiable variations are shown in Table 3. A comparison of these findings with those in patients without such variations (Table 1) showed no significant difference between the two groups, except that patients with genomic variations tended to be younger and more often had history of consanguinity, compared to those without variations.

The results of bioinformatic prediction of the effect of these genomic variations are shown in Additional file 1: Table S1. None of the nine variations included in Table 2 was observed in any of the 30 healthy controls. Among patients with homozygous variations $(n=7)$, both parents were available for testing for four patients and one parent each was available for three patients; all of them showed the respective variation in heterozygous form. For the two patients with heterozygous variations, one parent each was available for testing; in either case, the tested parent too had the variation in a heterozygous form.

\section{Non-pathogenic variations}

Three non-synonymous variations were identified in several children with PFIC (Table 4). These variations also had a high frequency in various population databases as well as in our patients as well as controls, indicating their benign nature. Further, all the three non-synonymous variations were predicted by various bioinformatics software tools to be neutral (Additional file 1: Table S2). Hence, these were considered as non-pathogenic.

In addition, 12 synonymous variations (Additional file 1: Table S3) were also identified in several patients. These too had a high frequency in population databases as well as in our patient population, and hence were considered as non-pathogenic.

\section{Discussion}

In our study of 25 unrelated Indian children with PFIC phenotype, we found pathogenic or likely-pathogenic sequence variations in ATP8B1, $\mathrm{ABCB} 11$ or $\mathrm{ABCB} 4$ gene in seven and variations of unknown significance in two. In these 9 patients, a total of nine different variations, including three novel variations, were identified. The variations which are particularly frequent in the Caucasian and other populations were not found. No major variation was found in the remaining 16 kindreds.

No data are available on the genomic variations responsible for PFIC from India. The Indian population is genetically diverse with contribution from at least two highly divergent populations - i.e. the 'North Indians', genetically close to the Middle Easterners, Central Asians, and Europeans, and a distinct group termed as 'Ancestral South Indians' [31-33], with some contributions from the sub-Saharan and Middle Eastern lineages [34]. This may explain the diversity in genetic variations observed in our cohort, identification of 
Table 1 Clinical and laboratory features of patients included in the study $(n=25)$

\begin{tabular}{|c|c|c|c|c|}
\hline Clinical feature & $\begin{array}{l}\text { Value in all patients } \\
\text { studied }(n=25)\end{array}$ & $\begin{array}{l}\text { Value in those with } \\
\text { genomic } \\
\text { variation }(n=9)\end{array}$ & $\begin{array}{l}\text { Value in those without } \\
\text { genomic variation } \\
(n=16)\end{array}$ & $\begin{array}{l}p \text { value (with genomic } \\
\text { variation versus } \\
\text { without genomic } \\
\text { variation) }\end{array}$ \\
\hline Age at presentation (months) & $15(1-144)$ & $15(3-144)$ & $23(1-48)$ & 0.089 \\
\hline Age at onset of symptoms (months) & $5(0.25-138)$ & $3.5(0.25-138)$ & $5(0-18)$ & 1.123 \\
\hline Male (number) & $19(76 \%)$ & 7 & 12 & 1.000 \\
\hline History of consanguinity (number) & $7(28 \%)$ & 5 & 2 & 0.058 \\
\hline History of cholestasis of pregnancy (number) & $10(40 \%)$ & 3 & 7 & 0.691 \\
\hline Intense pruritus (number) & $24(96 \%)$ & 8 & 16 & 0.360 \\
\hline History of skin bleeding (number) & $17(68 \%)$ & 5 & 12 & 0.394 \\
\hline Jaundice (number) & $25(1)$ & 9 & 16 & 1.000 \\
\hline Weight z score ${ }^{a}$ & $-2.08(-3.55$ to +0.32$)$ & $-2.35(-3.55$ to +0.32$)$ & $-1.98(-3.52$ to +0.21$)$ & 0.205 \\
\hline Height z score ${ }^{b}$ & $-1.63(-5.62$ to +2.26$)$ & $-1.55(-4.75$ to +0.2$)$ & $-1.73(-5.62$ to +2.26$)$ & 0.478 \\
\hline Palpable liver below right costal margin $(\mathrm{cm})^{c}$ & $4(1-8)$ & $3(2-8)$ & $4(1-7)$ & 0.790 \\
\hline Palpable spleen below left costal margin $(\mathrm{cm})^{\mathrm{d}}$ & $2(1-5)$ & $1(1-5)$ & $3(2-4)$ & 0.300 \\
\hline Total serum bilirubin (mg/dL) & $7.0(1.3-32.0)$ & $12.7(1.3-21.0)$ & $6.6(1.7-32.0)$ & 0.296 \\
\hline Serum albumin $(g / d L)^{e}$ & $3.7(2.7-4.5)$ & $3.8(3.2-4.2)$ & $3.8(2.7-4.5)$ & 0.777 \\
\hline Serum aspartate aminotransferase (U/L) & $175(45-1210)$ & $92(45-1120)$ & $214(69-1210)$ & 0.844 \\
\hline Serum alanine aminotransferase (U/L) & $142(29-682)$ & $96(29-598)$ & $104(30-682)$ & 0.947 \\
\hline Serum gamma-glutamyl transpeptidase (U/L) & $28(8-69)$ & $25(8-57)$ & $33.5(11-69)$ & 0.154 \\
\hline
\end{tabular}

Data are shown as median (range), or as number (\%)

a Values less than 2.0 were observed in 13 children, including $5 / 9$ with and $8 / 16$ without genomic variations $(p=1.00)$

b Values less than 2.0 were observed in 10 children, including $4 / 9$ with and $6 / 16$ without genomic variations $(p=1.00)$

'Liver was palpable in all the 25 children

${ }^{d}$ Spleen was palpable in 16 of the 25 children: including 5/9 with and 11/16 without genomic variations $(p=0.67)$

${ }^{e}$ Serum albumin level was abnormally low $(<3.5 \mathrm{~g} / \mathrm{dL})$ in 3 of 25 children: including $1 / 9$ with and $2 / 16$ without genomic variations $(p=1.00)$

novel variations and the difference in variations in our patients from those reported in the other population groups. The diversity of variations in our patients suggests that it will be difficult to identify a panel of few common variations for diagnostic testing in Indian patients with PFIC.

We encountered three novel variations. One of these (p.Gly197LeufsTer10) was expected to lead to production of a truncated ATP8B1 protein (of 205-amino acid length instead of the usual 1251 amino acids), which would lack a part of the E1-E2 ATPase domain (aa 170234), and the entire cation ATPase (aa 533-628) and phospholipase ATPase C domains (aa 919-1174), and hence be non-functional. This patient has been described in detail elsewhere as a case report [16]. Another variation (p.Val454*) led to a truncated ABCB11 protein. Both these truncation variations would be clearly expected to be pathogenic even without any functional studies to study their biological effect. The third novel variation affected a splice donor site in the ABCB11 gene, and was heterozygous. Demonstration of its functional effect needed sequencing of the patient's liver transcriptome; however, a liver biopsy for this purpose was considered ethically unacceptable. This patient also had a heterozygous p.Val444Ala variation, which is known to cause a reduction in enzyme activity, and this may explain the occurrence of disease in him despite the novel splice site variation being heterozygous.

Variations observed in our remaining six patients had been reported previously in other population groups. Of these, three were in ATP8B1 gene and had been previously shown to be associated with disease. First, an in-frame deletion (p.Phe529del) had been previously reported in two patients - in homozygous form in a Japanese patient with severe disease needing liver transplant by 4 years of age $[2,35]$, and in compound heterozygous form with a splice site variation in a patient of mixed Caucasian-African American ancestry [2]. Our patient was homozygous for this variation and had a severe illness. Second, a p.Asp554Asn substitution had been previously reported in three Inuit patients [19, 36, 37]. It affects a centrally-located aspartate residue in the AASPDEGALV motif, specific for P-type ATPases [38], and was associated in an in vitro study with an absent expression of ATP8B1 on canalicular membranes [39]. Third, a p.Glu981Lys substitution had been previously reported in a Japanese patient with PFIC [40], and the mutant protein was shown to have a reduced interaction 


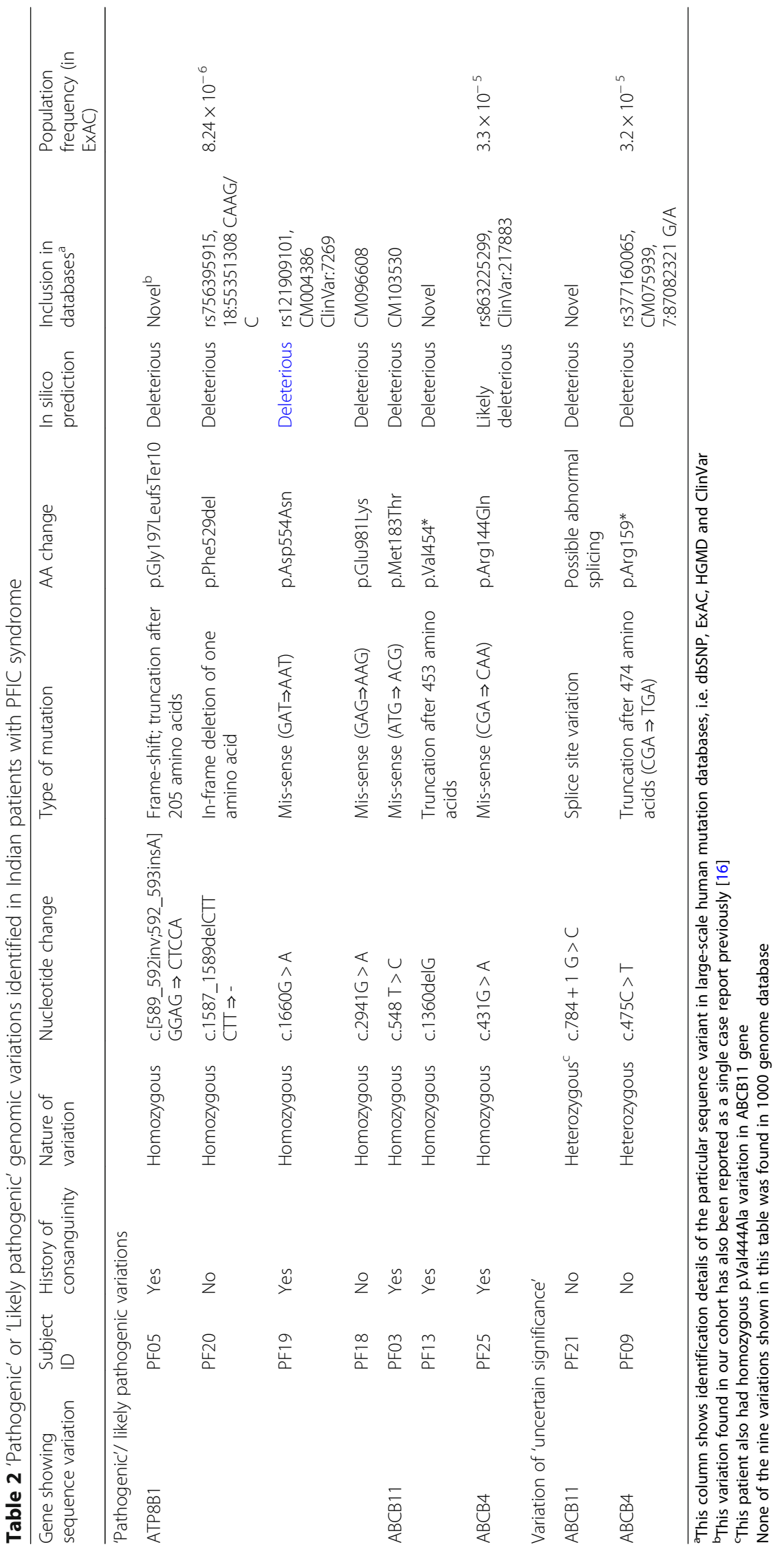




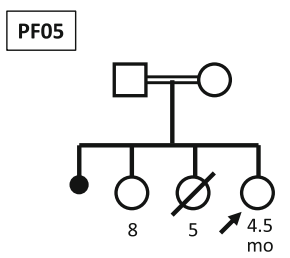

PF18

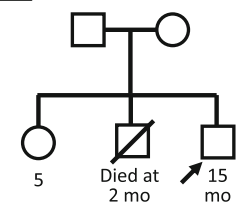

PF13

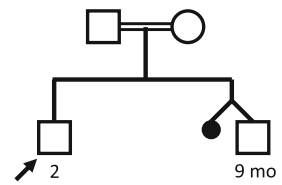

PF20

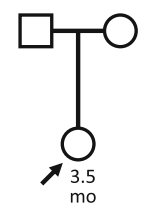

PF03

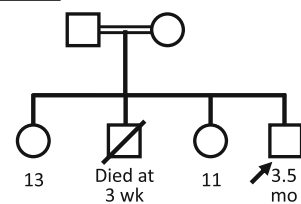

PF25

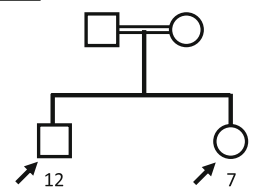

PF19

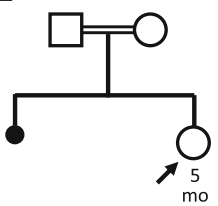

PF21

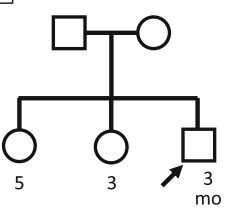

PF09

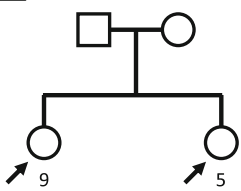

Fig. 1 Family tree for 9 patients in whom major variations in ATP8B1 (patients PF05, PF20, PF19 and PF18), ABCB11 (patients PF03, PF21 and PF13) or ABCB4 (patients PF25 and PF09) genes were found. Five of these nine patients had history of consanguinity. Clinical, biochemical and histological findings in these patients are included in Table 3

with its substrate leading to a nearly $80 \%$ reduction in its activity in a yeast-cell model [41].

Of the remaining three previously-reported variations, one was in ABCB11 gene. This variation in ABCB11 gene (p.Met183Thr) had been previously reported in a patient with PFIC2, who had a compound heterozygous state [42]; in our patient, this variation was homozygous. Of the two previously-known variations in the ABCB4 gene identified in our patients, one (p.Arg159*) was previously reported in an Italian patient in heterozygous state [43], with no genomic variation on the other allele. This is similar to the findings in our patient, who had an elder sibling with similar illness, and in whom the symptoms appeared at 54 months of age. Given that PFIC3 is well recognized to have an autosomal recessive inheritance, one would expect another variation on the other allele of this gene, which however could not be identified. The other ABCB4 variation (p.Arg144Gln) that we observed has not been reported in patients with PFIC; however, it is likely to be pathogenic since it was predicted to be deleterious, was present in homozygous form and had a low population frequency.

We also identified some missense and synonymous variations which were frequent in population-level genetic databases, and were predicted not to adversely affect protein structure or function, and hence were considered 'benign' or 'likely benign'. One of these, the c.1331 T C (p.Val444Ala) substitution in ABCB11 gene may need particular mention. This variation has previously been variably reported to be associated with reduced activity of the protein and disease [44]. As discussed above, this substitution was identified in a patient who also had a heterozygous novel splice-site variation in this gene, and hence could have played in role in disease causation in that patient.

Importantly, no coding region or splice-site variation was identified in any of the three genes studied in 16 of our 25 patients. This could have several explanations. In studies from other geographical regions too, variations are identified in only $30-50 \%$ of cases with PFIC phenotype [2, 42]. Second, we did not look for variations in the promoter and non-coding regions; however, such variations are only infrequently responsible for disease. Third, our methods could miss a heterozygous major deletion; however, such a deletion would need a pathogenic variation on the other allele to cause disease. Fourth, we did not study variations in other genes involved in bile acid transport (such as MYO5B, TJP2, NR1H4, FXR or VIPAS39) [45-49]. It should be possible to work around some of these limitations in future, by using whole exome or whole genome sequencing. Finally, it is possible that some of our patients may not have had PFIC, even though we took precautions to exclude other liver diseases.

As expected, we identified genomic variations more often in patients with history of consanguinity $(5 / 7 ; 71 \%)$ than in those without $(4 / 18 ; 22 \%)$. In the two patients who had homozygous variations in the absence of history of consanguinity, the parents may have had some shared ancestry which was missed on history taking; this is possible with close inbreeding prevalent in some communities in India. 


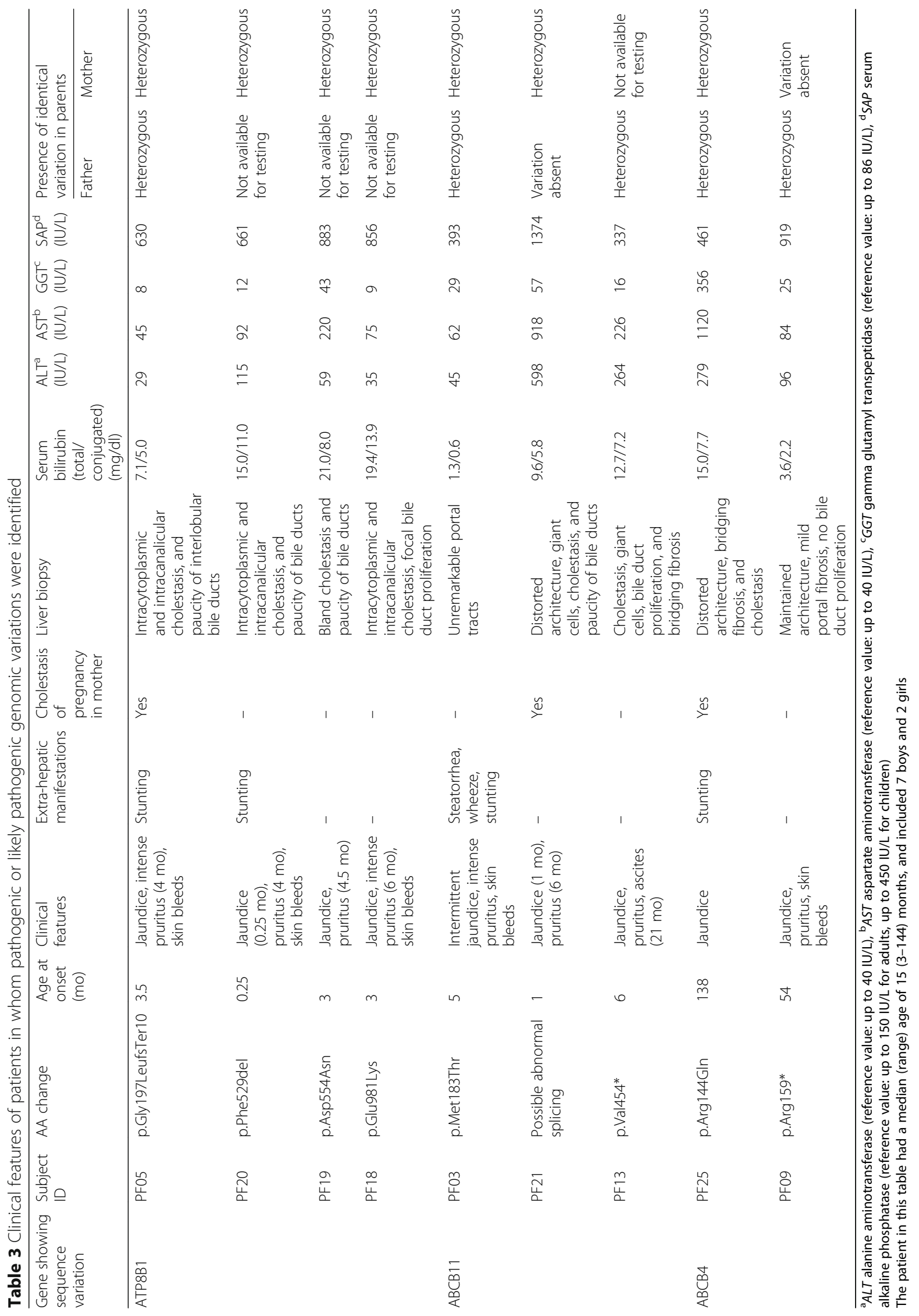




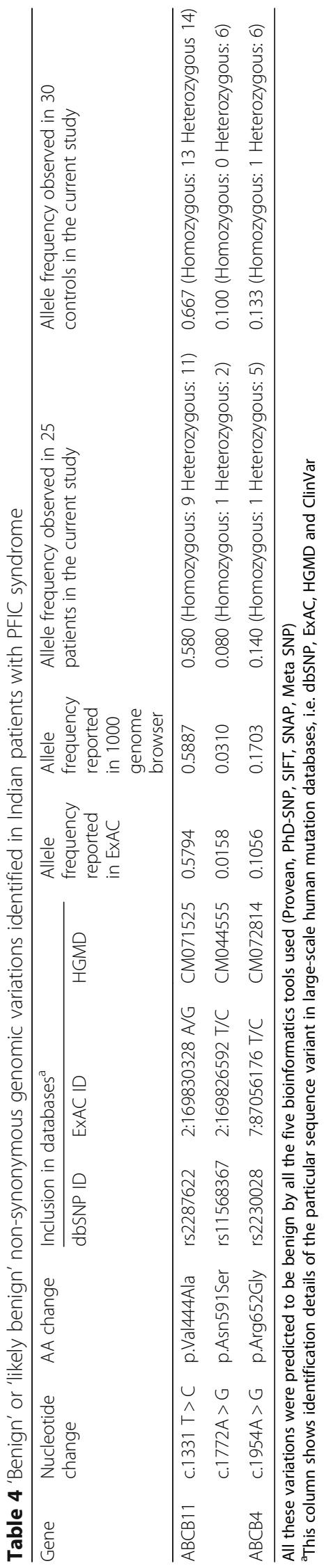




\section{Conclusions}

Our study identified major genomic variations in only about one-third of Indian children with PFIC. None of the nine variations that we identified was particularly frequent, and three of these were novel. Further, our findings suggest that genomic variations responsible for PFIC in Indian patients may differ from those in other populations. Since we did not find any genomic variation in nearly two-thirds of our patients, it may be useful to undertake whole-exome or whole-genome sequencing studies in Indian children with PFIC to look for variations in promoter/intronic regions of the ATP8B1, ABCB11 and $\mathrm{ABCB} 4$ genes and in other genes involved in bile salt transport.

\section{Additional file}

Additional file 1: Table S1. Results of prediction of effect, using various bioinformatic tools, of various 'pathogenic' or 'likely pathogenic' nonsynonymous genomic variations. Table S2. Results of prediction of effect, using various bioinformatic tools, of various 'neutral' non-synonymous genomic variations. Table S3. Synonymous genomic variations identified in Indian patients with PFIC syndrome (DOCX 24 kb).

\section{Abbreviations}

BSEP: Bile salt export pump; ExAC: Exome Aggregation Consortium; GGT: Gamma-glutamyl transpeptidase; HGMD: Human Genome Mutation Database; MDR3: Multidrug resistance protein 3; NCBI: National Centre for Biotechnology Information; PFIC: Progressive familial intrahepatic cholestasis

\section{Funding}

This study was not supported by any specific research grant. During this work, AS and SA were supported by Indian Council of Medical Research, New Delhi. The sequencing facility at the authors' institution was set up with the help of Department of Science \& Technology, Government of India. The Bioinformatics Centre at the Sanjay Gandhi Postgraduate Institute of Medical Sciences is supported by a grant from the Indian Council of Medical Research, New Delhi.

\section{Availability of data and materials}

The datasets generated during the current study are available from the corresponding author on reasonable request. The data on variations will be submitted to the GenBank.

\section{Authors' contributions \\ RA, UP and SP designed the study. UP and SKY were responsible for clinical characterization and enrolment of the study subjects. AS performed the laboratory experiments and was responsible for data acquisition. AS, SA, RA and SP were responsible for analysis and interpretation of data. AS and SA wrote the first draft of the manuscript. All the authors were involved in critical revision of the manuscript and approved the final version. \\ Ethics approval and consent to participate \\ The study was approved by Ethics Committee of the Sanjay Gandhi Postgraduate Institute of Medical Sciences, Lucknow, India. An informed written consent was obtained from one of the parents for each child studied.}

\section{Consent for publication}

The consent document for study subjects included consent for publication of data (after removing any identifying information).

\section{Competing interests}

The authors declare that they have no competing interests.

\section{Publisher's Note}

Springer Nature remains neutral with regard to jurisdictional claims in published maps and institutional affiliations.

\section{Author details}

${ }^{1}$ Department of Gastroenterology, Sanjay Gandhi Postgraduate Institute of Medical Sciences, Lucknow 226014, India. ²Department of Pediatric

Gastroenterology, Sanjay Gandhi Postgraduate Institute of Medical Sciences, Lucknow 226014, India. ${ }^{3}$ Department of Medical Genetics, Sanjay Gandhi

Postgraduate Institute of Medical Sciences, Lucknow 226014, India.

Received: 21 March 2018 Accepted: 26 June 2018

Published online: 04 July 2018

\section{References}

1. Davit-Spraul A, Gonzales E, Baussan C, Jacquemin E. Progressive familial intrahepatic cholestasis. Orphanet J Rare Dis. 2009:4:1. https://doi.org/10. 1186/1750-1172-4-1.

2. Klomp LW, Vargas JC, van Mil SW, Pawlikowska L, Strautnieks SS, van Eijk MJ, et al. Characterization of mutations in ATP8B1 associated with hereditary cholestasis. Hepatology. 2004;40:27-38. https://doi.org/10. 1002/hep.20285.

3. Strautnieks SS, Byrne JA, Pawlikowska L, Cebecauerova D, Rayner A, Dutton $L$, et al. Severe bile salt export pump deficiency: 82 different ABCB11 mutations in 109 families. Gastroenterology. 2008;134(4):1203-14. https://doi.org/10.1053/j.gastro.2008.01.038.

4. Davit-Spraul A, Gonzales E, Baussan C, Jacquemin E. The spectrum of liver diseases related to $A B C B 4$ gene mutations: pathophysiology and clinical aspects. Semin Liver Dis. 2010;30:134-46. https://doi.org/10.1055/s-0030-1253223.

5. Wang NL, Li LT, Wu BB, Gong JY, Abuduxikuer K, Li G, et al. The features of GGT in patients with ATP8B1 or ABCB11 deficiency improve the diagnostic efficiency. PLoS One. 2016;11:e0153114. https://doi.org/10.1371/journal.pone.0153114.

6. Lykavieris P, van Mil S, Cresteil D, Fabre M, Hadchouel M, Klomp L, et al. Progressive familial intrahepatic cholestasis type 1 and extrahepatic features: no catch-up of stature growth, exacerbation of diarrhea, and appearance of liver steatosis after liver transplantation. J Hepatol. 2003;39:447-52.

7. Van der Velden LM, Stapelbroek JM, Krieger E, van den Berghe PV, Berger R, Verhulst PM, et al. Folding defects in P-type ATP 8B1 associated with hereditary cholestasis are ameliorated by 4-phenylbutyrate. Hepatology. 2010;51:286-96. https://doi.org/10.1002/hep.23268.

8. Liu LY, Wang XH, Wang ZL, Zhu QR, Wang JS. Characterization of ATP8B1 gene mutations and a hot-linked mutation found in Chinese children with progressive intrahepatic cholestasis and low GGT. J Pediatr Gastroenterol Nutr. 2010;50:179-83. https://doi.org/10.1097/MPG.0b013e3181c1b368.

9. Shagrani M, Burkholder J, Broering D, Abouelhoda M, Faquih T, El-Kalioby M, et al. Genetic profiling of children with advanced cholestatic liver disease. Clin Genet. 2017;92:52-61. https://doi.org/10.1111/cge.12959.

10. Koshy A, Ramesh H, Mahadevan P, Mukkada RJ, Francis VJ, Chettupuzha AP, et al. Progressive familial intrahepatic cholestasis: a case with improvement in liver tests and growth following partial external biliary diversion. Indian J Gastroenterol. 2009;28:107-8. https://doi.org/10.1007/s12664-009-0038-8. doi: 10.1007/s12664-009-0038-8.

11. Sharma D, Shah UH, Sibal A, Chowdhary SK. Cholecystoappendicostomy for progressive familial intrahepatic cholestasis. Indian Pediatr. 2010;47:626-8.

12. Ganesh $R$, Suresh N, Sathiyasekeran M, Ramachandran P. Partial internal biliary diversion: a solution for intractable pruritus in progressive familial intrahepatic cholestasis type 1. Saudi J Gastroenterol. 2011;17:212-4. https://doi.org/10.4103/1319-3767.80387.

13. Kaur S, Sharma D, Wadhwa N, Gupta S, Chowdhary SK, Sibal A. Therapeutic interventions in progressive familial intrahepatic cholestasis: experience from a tertiary care Centre in North India. Indian J Pediatr. 2012;79:270-3. https://doi.org/10.1007/s12098-011-0516-8.

14. Ramachandran $P$, Shanmugam NP, Sinani SA, Shanmugam V, Srinivas $S$, Sathiyasekaran M, et al. Outcome of partial internal biliary diversion for intractable pruritus in children with cholestatic liver disease. Pediatr Surg Int. 2014;30:1045-9. https://doi.org/10.1007/s00383-014-3559-x.

15. Agarwal S, Lal BB, Rawat D, Rastogi A, Bharathy KG, Alam S. Progressive familial intrahepatic cholestasis (PFIC) in Indian children: clinical spectrum and outcome. J Clin Exp Hepatol. 2016;6:203-8. https://doi.org/10.1016/j. jceh.2016.05.003. 
16. Sharma A, Poddar U, Agnihotry S. Aggarwal R. A novel truncation mutation in ATP8B1 gene in progressive familial intrahepatic cholestasis. Indian Pediatr. 2016;53:1099-101.

17. Jacquemin E. Progressive familial intrahepatic cholestasis. Clin Liver Dis. 2000;4:753-63.

18. Sambrook J, Russell DW. Purification of nucleic acids by extraction with phenol: chloroform. Cold Spring Harb Protoc. 2006;2006:pdb. prot4455. https://doi.org/10.1101/pdb.prot4455.

19. Klomp LW, Bull LN, Knisely AS, van Der Doelen MA, Juijn JA, Berger R, et al. A missense mutation in FIC1 is associated with Greenland familial cholestasis. Hepatology. 2000;32:1337-41. https://doi.org/10.1053/jhep.2000.20520.

20. Van Mil SW, van der Woerd WL, van der Brugge G, Sturm E, Jansen PL, Bull $L N$, et al. Benign recurrent intrahepatic cholestasis type 2 is caused by mutations in ABCB11. Gastroenterology. 2004;127:379-84

21. Lang T, Haberl M, Jung D, Drescher A, Schlagenhaufer R, Keil A, et al. Genetic variability, haplotype structures, and ethnic diversity of hepatic transporters MDR3 (ABCB4) and bile salt export pump (ABCB11). Drug Metab Dispos. 2006;34:1582-99. https://doi.org/10.1124/dmd.105.008854

22. Choi Y, Chan AP. PROVEAN web server: a tool to predict the functional effect of amino acid substitutions and indels. Bioinformatics. 2015;31:27457. https://doi.org/10.1093/bioinformatics/btv195.

23. Schwarz JM, Rodelsperger C, Schuelke M, Seelow D. MutationTaster evaluates disease-causing potential of sequence alterations. Nat Methods. 2010;7:575-6. https://doi.org/10.1038/nmeth0810-575.

24. Adzhubei I, Jordan DM, Sunyaev SR. Predicting functional effect of human missense mutations using PolyPhen-2. Curr Protoc Hum Genet. 2013; Chapter 7:Unit7.20; https://doi.org/10.1002/0471142905.hg0720s76. PubMed PMID: 23315928; PubMed Central PMCID: PMC4480630.

25. Capriotti E, Calabrese R, Casadio R. Predicting the insurgence of human genetic diseases associated to single point protein mutations with support vector machines and evolutionary information. Bioinformatics. 2006;22: 2729-34. https://doi.org/10.1093/bioinformatics/btl423.

26. Kumar P, Henikoff S, Ng PC. Predicting the effects of coding nonsynonymous variants on protein function using the SIFT algorithm. Nat Protoc. 2009;4:1073-81. https://doi.org/10.1038/nprot.2009.86.

27. Bromberg Y, Rost B. SNAP: predict effect of non-synonymous polymorphisms on function. Nucleic Acids Res. 2007;35:3823-35. https://doi. org/10.1093/nar/gkm238

28. Capriotti E, Altman RB, Bromberg Y. Collective judgment predicts diseaseassociated single nucleotide variants. BMC Genomics. 2013;14:S2. https://doi. org/10.1186/1471-2164-14-S3-S2.

29. Desmet FO, Hamroun D, Lalande M, Collod-Beroud G, Claustres M, Beroud C. Human splicing finder: an online bioinformatics tool to predict splicing signals. Nucleic Acids Res. 2009;37:e67. https://doi.org/10.1093/nar/gkp215.

30. Richards S, Aziz N, Bale S, Bick D, Das S, Gastier-Foster J, et al. Standards and guidelines for the interpretation of sequence variants: a joint consensus recommendation of the American College of Medical Genetics and Genomics and the Association for Molecular Pathology. Genet Med. 2015; 17:405-24. https://doi.org/10.1038/gim.2015.30.

31. Reich D, Thangaraj K, Patterson N, Price AL, Singh L. Reconstructing Indian population history. Nature. 2009;461:489-94. https://doi.org/10.1038/ nature08365.

32. Tamang $R$, Singh $L$, Thangaraj K. Complex genetic origin of Indian populations and its implications. J Biosci. 2012;37:911-9.

33. Moorjani P, Thangaraj K, Patterson N, Lipson M, Loh PR, Govindaraj P, et al. Genetic evidence for recent population mixture in India. Am J Hum Genet. 2013;93:422-38. https://doi.org/10.1016/j.ajhg.2013.07.006.

34. Eaaswarkhanth M, Haque I, Ravesh Z, Romero IG, Meganathan PR, Dubey B, et al. Traces of sub-Saharan and middle eastern lineages in Indian Muslim populations. Eur J Hum Genet. 2010;18:354-63. https://doi.org/10.1038/ejhg.2009.

35. Egawa H, Yorifuji T, Sumazaki R, Kimura A, Hasegawa M, Tanaka K Intractable diarrhea after liver transplantation for Byler's disease: successful treatment with bile adsorptive resin. Liver Transpl. 2002;8: 714-6. https://doi.org/10.1053/jlts.2002.34384

36. Eiberg $H$, Norgaard-Pedersen B, Nielsen IM. Cholestasis familiaris groenlandica/Byler-like disease in Greenland-a population study. Int J Circumpolar Health. 2004;63:189-91

37. Andersen S, Okkels H, Krarup H, Laurberg P. Geographical clustering and maintained health in individuals harbouring the mutation for Greenland familial cholestasis: a population-based study. Scand J Gastroenterol. 2006; 41:445-50. https://doi.org/10.1080/00365520510024250.
38. Catty P, de Kerchove d'Exaerde A, Goffeau A. The complete inventory of the yeast Saccharomyces cerevisiae P-type transport ATPases. FEBS Lett. 1997: 409:325-32.

39. Folmer DE, van der Mark VA, Ho-Mok KS, Oude Elferink RP, Paulusma CC. Differential effects of progressive familial intrahepatic cholestasis type 1 and benign recurrent intrahepatic cholestasis type 1 mutations on canalicular localization of ATP8B1. Hepatology. 2009;50:1597-605. https://doi.org/10.1002/hep.23158.

40. Numakura C, Abukawa D, Kimura T, Tanabe S, Hayasaka K. A case of progressive familial intrahepatic cholestasis type 1 with compound heterozygous mutations of ATP8B1. Pediatr Int. 2011;53:107-10. https://doi.org/10.1111/j.1442-200X.2010.03238.X.

41. Stone A, Chau C, Eaton C, Foran E, Kapur M, Prevatt E, et al. Biochemical characterization of P4-ATPase mutations identified in patients with progressive familial intrahepatic cholestasis. J Biol Chem. 2012;287:41139-51. https://doi.org/10.1074/jbc.M112.413039.

42. Davit-Spraul A, Fabre M, Branchereau S, Baussan C, Gonzales E, Stieger B, et al. ATP8B1 and ABCB11 analysis in 62 children with normal gammaglutamyl transferase progressive familial intrahepatic cholestasis (PFIC): phenotypic differences between PFIC1 and PFIC2 and natural history. Hepatology. 2010;51:1645-55. https://doi.org/10.1002/hep.23539.

43. Degiorgio D, Crosignani A, Colombo C, Bordo D, Zuin M, Vassallo E, et al. ABCB4 mutations in adult patients with cholestatic liver disease: impact and phenotypic expression. J Gastroenterol. 2016;51:271-80. https://doi.org/10.1007/s00535-015-1110-Z

44. Hsu YC, Chen HL, Wu MZ, Liu YJ, Lee PH, Sheu JC, et al. Adult progressive intrahepatic cholestasis associated with genetic variations in ATP8B1 and ABCB11. Hepatol Res. 2009;39:625-31. https://doi.org/10.1111/j.1872-034X. 2009.00499.x.

45. Qiu YL, Gong JY, Feng JY, Wang RX, Han J, Liu T, et al. Defects in myosin VB are associated with a spectrum of previously undiagnosed low ү-glutamyltransferase cholestasis. Hepatology. 2017;65:1655-69. https://doi.org/10.1002/hep.29020

46. Sambrotta M, Strautnieks S, Papouli E, Rushton P, Clark BE, Parry DA, et al. Mutations in TJP2 cause progressive cholestatic liver disease. Nat Genet. 2014;46:326-8. https://doi.org/10.1038/ng.2918.

47. Davit-Spraul A, Gonzales E, Jacquemin E. NR1H4 analysis in patients with progressive familial intrahepatic cholestasis, drug-induced cholestasis or intrahepatic cholestasis of pregnancy unrelated to ATP8B1, ABCB11 and ABCB4 mutations. Clin Res Hepatol Gastroenterol. 2012;36:569-73. https://doi.org/10.1016/j.clinre.2012.08.008

48. Cariello M, Piccinin E, Garcia-Irigoyen O, Sabbà C, Moschetta A. Nuclear receptor FXR, bile acids and liver damage: introducing the progressive familial intrahepatic cholestasis with FXR mutations. Biochim Biophys Acta. 2018;1864(4 Pt B):1308-18. https://doi.org/10.1016/j.bbadis.2017.09.019.

49. Seo SH, Hwang SM, Ko JM, Ko JS, Hyun YJ, Cho SI, Park H, Kim SY, Seong MW, Park SS. Identification of novel mutations in the VPS33B gene involved in arthrogryposis, renal dysfunction, and cholestasis syndrome. Clin Genet. 2015;88:80-4. https://doi.org/10.1111/cge.12442.

Ready to submit your research? Choose BMC and benefit from

- fast, convenient online submission

- thorough peer review by experienced researchers in your field

- rapid publication on acceptance

- support for research data, including large and complex data types

- gold Open Access which fosters wider collaboration and increased citations

- maximum visibility for your research: over $100 \mathrm{M}$ website views per year

At BMC, research is always in progress.

Learn more biomedcentral.com/submissions 